\title{
Argentina's Lost Decade and the Subsequent Recovery Puzzle
}

\author{
Finn E. Kydland and Carlos E. J. M. Zarazaga
}

The unusual features and severity of the Great Depression in the United States have been the object of much speculation among economists and social scientists, intrigued by a phenomenon still resistant to a widely accepted explanation. Lack of progress in understanding the Great Depression may be attributed, at least in part, to the unavoidable limitations of the "event study" methodology with which most scholars have approached the "case," possibly out of the perception that the Great Depression was an episode so rare that it is the only experience with depressions available for study in actual economies.

In addition, implicit in that case study approach to the Great Depression is often the view that depressions are rare not just in frequency but also in nature. That is, that they represent an essential "discontinuity" with the past and the future, perhaps because, for reasons not fully understood, the behavior that economic agents typically display in normal times is suspended, as it were, during economic depressions and replaced with a different one. The difficulty with this view is that the very rarity of depressions conspires against the ability to identify which elements, if any, of the economic environment or agents' behavior and expectations during economic depressions are substantially different, to the point of discontinuity, from more normal times.

That is an unfortunate state of affairs, because protracted and severe depressions are not as rare as many scholars seem inclined to believe. In fact, this paper has been motivated by the evidence that not long ago, during the 1980s (the so-called lost decade), Argentina experienced a rather severe economic depression as defined in this volume: ${ }^{1}$ detrended output per working-age population declined along that decade a stunning 30 percent, and it was nearly 20 percent below trend by the time the decade was over. 
Faced with this evidence, it is only natural to ask, Can standard growth theory account for the economic depression of Argentina's lost decade? In this paper we answer this question in the affirmative: our numerical experiments for a parsimonious neoclassical growth model that takes total factor productivity (TFP) as exogenous generate paths for real GDP per capita, capital input, and the capital-output ratio that are strikingly close to the actual paths of those variables during the lost decade.

We interpret those findings as evidence that economic depressions are not necessarily associated with any abnormal deviations or discontinuity in the formation of expectations or in the behavior of economic agents from normal times.

Somewhat surprisingly, the paper uncovers that if there was any abnormal or discontinuous behavior in the light of the neoclassical growth model, it was not during the depression years of the lost decade but in the subsequent recovery: capital accumulation during the expansion of the 1990s proceeded at a lower rate than the same neoclassical growth model would have predicted. We conjecture that accounting for this anomaly might be as important for understanding Argentina's growth experience as it is to account for that country's lost decade years. Furthermore, since Cole and Ohanian (1999) report a similar "success" of the neoclassical growth model to account for the U.S. Great Depression and a similar "failure" to account for the recovery that followed, the resolution of the "1990s puzzle" for Argentina may have potentially important implications for growth theory in general and, as such, is an interesting research topic in its own right.

In fact, it was precisely to be able to uncover regularities across countries like the ones just reported for the United States and Argentina that this paper, in the spirit of this volume, examines Argentina's growth experience during the depression of the 1980s and the recovery of the 1990s exclusively through the lens of the neoclassical growth model. In so doing, we do not imply that the neoclassical growth model is the only relevant one for the study of economic depressions. Rather, the hope is that studying economic depressions (and subsequent recoveries) with that same model across countries might lead to insights into the nature of depressions and of economic growth in general that would not be possible with the limitations inherent to the event study approach mentioned earlier.

A quick summary of our methodology is as follows: we compute the TFP time series (Solow residuals) of a typical constant-returns-to-scale production function with standard growth accounting methods and calibrate a parsimonious neoclassical growth model to the Argentine economy during "normal times," or more rigorously speaking, to its implied steady state. We then compute the economic agents' decision rules under the assumption of rational 
expectations and feed the measured Solow residuals into the model economy to generate the paths for real gross domestic product (GDP) per capita, capital stock, and employment (number of workers) induced by those decision rules. The comparison of the model-generated path for each variable with the actual data for the same variable makes it possible to infer the extent to which variations of such variables during the lost decade years and subsequent recovery can be accounted for by the actually observed TFP shocks.

\section{Overview of the Argentine Growth Experience}

Figure 1 offers a quick overview of Argentina's economic growth in the second half of the twentieth century. It plots an index of real GDP per working-age person from 1950 to 1997 , detrended by the average growth rate (1.01 percent) of the labor augmenting technological progress (the TFP factor) for the period 1951-79, a choice more thoroughly justified later, in the section of the paper devoted to the calibration of the model economy to Argentina's long-run growth features.

According to Figure 1 and as anticipated in the introduction, by the end of the lost decade, in 1990, Argentina's detrended GDP per capita had fallen a striking 30 percent below its level of ten years earlier and 20 percent below trend.

To identify the sources of growth, we undertook a growth accounting exercise. Appendix B outlines our data sources and the method we used in constructing these series relevant to that end.

Figure 1. Detrended GDP per working-age population, 1950-97

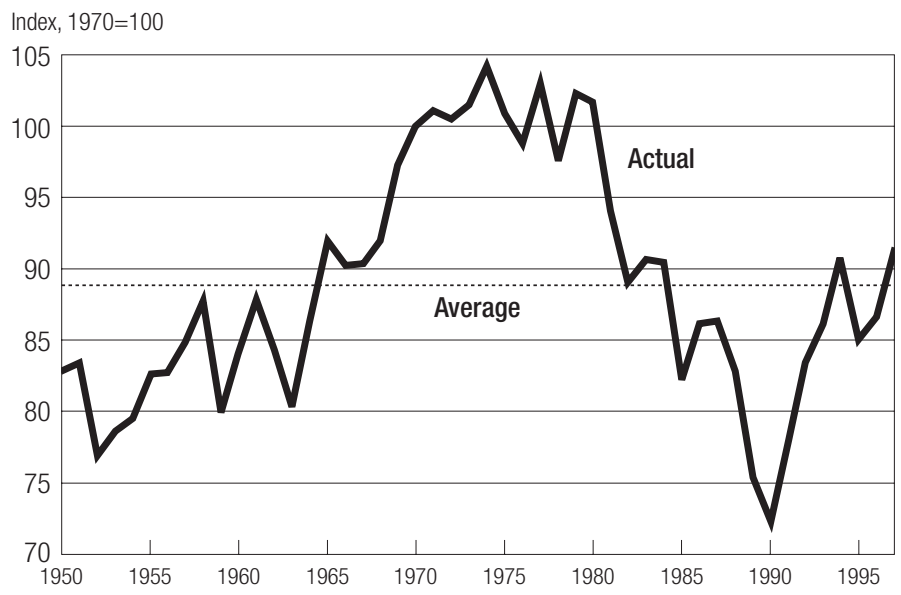


In our growth accounting exercise, we assume that the production function is given by

$$
\text { (1) } Y_{t}=z_{t} K_{t}^{\theta} L_{t}^{1-\theta}
$$

where $Y$ is aggregate output, $A$ is TFP, $K$ is aggregate capital, and $L$ is aggregate employment.

Our growth accounting differs in appearance but is equivalent to standard growth accounting. We decompose output per capita into three factors: the TFP factor $A^{1 /(1-\theta)}$, employment intensity $(L)$, and the capital intensity factor $(K / Y)^{\theta /(1-\theta)}$. This decomposition is convenient because the growth rate of the efficiency factor coincides with the trend growth rate of output per adult when employment per capita and capital intensity are constant, as they should be along the balanced-growth path. ${ }^{2}$

Table 1 presents the results of our growth accounting exercise for a capital share of 0.4 (see our discussion below on calibration).

From 1951 to 1979, GDP per working-age person grew at a 1.7 percent annual rate. TFP and capital intensity contributed about equally to that growth, while employment intensity subtracted about 0.2 percentage points from it. Within this period, the 1960s stand out for rapid 3 percent GDP growth, accounted almost entirely by productivity gains. The 1950s and 1970s, on the other hand, reveal capital intensity as the only factor making significant positive contributions to GDP growth in those two decades, when TFP exhibited a relatively poor performance, in particular in the 1970s, during which it declined at an average annual rate of 0.15 percent. $^{3}$

The observation that capital intensity contributed about 1 percent on av-

Table 1. Accounting for growth, 1951-97

\begin{tabular}{lcccc}
\hline & & \multicolumn{3}{c}{ Factor } \\
\cline { 3 - 5 } Time period & $\begin{array}{c}\text { GDP per } \\
\text { working-age } \\
\text { person (\%) }\end{array}$ & TFP factor (\%) & $\begin{array}{c}\text { Capital } \\
\text { intensity (\%) }\end{array}$ & $\begin{array}{c}\text { Employment } \\
\text { intensity (\%) }\end{array}$ \\
\hline $1951-59$ & 0.47 & 0.17 & 1.31 & -1.00 \\
$1959-69$ & 3.01 & 2.96 & 0.01 & 0.03 \\
$1969-79$ & 1.51 & -0.25 & 1.54 & 0.23 \\
$1951-79$ & 1.74 & 1.01 & 0.93 & -0.19 \\
$1979-90$ & -2.12 & -3.25 & 0.83 & 0.34 \\
$1990-97$ & 4.45 & 7.16 & -2.75 & 0.25 \\
$1979-97$ & 0.38 & 0.67 & -0.59 & 0.30 \\
$1951-97$ & 1.21 & 0.88 & 0.33 & 0.00 \\
\hline
\end{tabular}


erage to the annual growth rates in the whole period 1951-79 suggests that Argentina may have not been growing along its balanced-growth path then, but rather that it was in the process of converging to the higher income per capita of more developed nations. The possible presence of transition dynamics over this period had implications for the calibration of the capital-output ratio, as discussed in a later section of this paper.

The mild decline of TFP during the 1970s already reported turned into an unprecedented collapse in the subsequent lost decade of the 1980s, during which the TFP factor fell at an average rate of 3 percent a year, that is, about the same rate at which it had increased instead during the $1960 \mathrm{~s} .{ }^{4}$ This collapse of productivity, moderated by mild increases in labor and capital intensity, more than accounted for the 2.1 percent average annual decline in GDP per capita during that depression.

The rather dramatic decline of TFP during the lost decade was followed by an impressive turnaround in the subsequent 1990-97 period. Output per capita grew at average rates 2.5 times higher than for the period 1951-79, driven by an unprecedented 7 percent TFP factor growth, partially offset by a rather deep decline in the capital intensity that hints at the "1990s excessive capital shallowing puzzle" that, as reported later, we regard as one of the relevant findings of this study.

Summing up, according to our growth accounting exercise, TFP seems to have been the dominant force behind Argentina's growth performance in the two decades that closed the last century. This feature of Argentina's recent growth experience, along with the observation that the neoclassical growth model takes TFP as exogenous, leads naturally to the question addressed in this paper: which percentage of the growth rates of the main macroeconomic variables (GDP, capital stock, employment) during those two decades can such a neoclassical growth model account for if subject to the same productivity shocks measured for Argentina over those same periods? The next section presents the tools and measures with which we will attempt to answer that question.

\section{Analytic Framework}

\section{Model}

We use the stochastic growth model. All variables are in per capita terms. Household preferences can be represented by

$$
E \sum_{t=0}^{\infty} \beta^{t}(1+\eta)^{t}\left(c_{t}^{\alpha}\left(1-l_{t}\right)^{1-\alpha}\right)^{1-\sigma} /(1-\sigma)
$$

where $c_{t}$ represents consumption, $l_{t}$ the fraction of the time endowment 
devoted to work, $\alpha$ the utility function share parameter, $\eta$ the population growth rate, and $\sigma$ the coefficient of constant relative risk aversion (or the reciprocal of the intertemporal elasticity of substitution of the composite commodity).

Technology is described by

$$
\begin{aligned}
& c_{t}+x_{t}=z_{t} k_{t}^{\theta}\left[(1+\gamma)^{t} l_{t}\right]^{1-\theta} \\
& x_{t}=(1+\gamma)(1+\eta) k_{t+1}-(1-\delta) k_{t} \\
& z_{t+1}=(1-\rho) \bar{z}+\rho z_{t}+\varepsilon_{t+1},
\end{aligned}
$$

where $k_{t}$ is the capital stock, $x_{t}$ is investment, $\theta$ is the capital input share in national income, and $z_{t}$ is a mean reverting (i.e., $|\rho|<1$ ) stochastic technological level, for which the innovation $\varepsilon_{t}$ is assumed to be an independently and identically distributed process with zero mean.

Notice the time-to-build assumption captured in the law of motion for capital, equation (4): investment in any given period begins to provide capital services on the next. It should be obvious from the notation as well that the model assumes labor-augmenting technological progress at the rate $\gamma$, also the rate at which output, consumption, and capital per person grow along the balanced-growth path. However, for the purposes of implementing the algorithm described later, a no-growth representation of this same economy is more convenient. To that end, following Hansen and Prescott (1995), the transformation $g_{t}^{*}=g_{t} /(1+\gamma)^{t}$ was applied to all per capita variables $g_{t}$ that according to the model grow at the common rate $(1+\gamma)$ along the balanced-growth path. To make this stationary version of the model economy equivalent with the original one with growth, the discount factor $\beta^{*}$ must be redefined as $\beta(1+\gamma)^{\alpha(1-\sigma)}$.

\section{Calibration}

The model economy is calibrated by choosing parameters so that the balanced-growth path mimics the actual economy on the dimensions associated with long-term growth (see Cooley and Prescott 1995).

We chose the period 1951-79 to establish the long-run features of Argentina's growth rather than the whole period for which the relevant data are available (1951-97) because, in the spirit of calibration, the period 1951-79 does not include any of the observations corresponding to the two decades that are the object of study in this paper. That is, we calibrate Argentina's economy to its long-run features as revealed by the information available to the economic agents by 1979 and ask whether a neoclassical growth model thus calibrated 
can account reasonably well for Argentina's relevant growth features afterward, during the lost decade and subsequent recovery of the 1990s.

Consistent with that choice of reference period, the following parameters (with their actual values in parentheses) were set to their average value over 1951-79: annual growth rate of working-age population (1.55 percent), labor-augmenting technological progress (TFP factor, 1.01 percent), and the depreciation rate (11.1 percent), the latter obtained by weighing the depreciation rates of the different components of investment (see Appendix B) by the participation of each of those components in total investment. Notice that the calibrated depreciation rate is in the order of magnitude of that used by Kydland and Prescott (1982).

It would be tempting to set the average capital-output ratio to its average over that period as well. However, unlike with the average TFP growth, this procedure is likely to underestimate the underlying long-run capital-output ratio if in the reference period the economy is not on the balanced-growth path, but converging to it from "above" or "below." As per the evidence discussed in the previous section, the latter seems to have been the case for Argentina during the reference period. Accordingly, the underlying long-run capital-output ratio is likely to be closer in magnitude to the ratios actually observed toward the end of that period than to their average over that same period. Given that the observed capital-output ratio for Argentina was still in an upward trend by the time it reached values of around 1.9 at the beginning of the lost decade, we adopted 2 as a reasonable guess for the value of that ratio in the long run. ${ }^{5}$

That calibrated capital-output ratio, in combination with the other parameters just calibrated, implies, via the law of motion of capital (4), an investment-output ratio of 0.273 along the balanced-growth path.

Another parameter that is particularly challenging to calibrate for the case of Argentina is the capital share parameter $\theta$ of the production function. The national income accounts typically used to that effect in countries like the United States are not available in Argentina, which can therefore estimate its GDP only from the product accounts. As a result, the labor and capital cost shares in GDP cannot be calculated directly from reported factor incomes. Therefore, we set the capital input share, $\theta$, to 0.40 , as if Argentina's production technology were the same as that of the United States. While some estimates have the capital share at 60 percent of GDP, most researchers consider that this figure would be closer to 40 percent were it not for the substantial underreporting of labor income in the informal sector of Argentina's economy. ${ }^{6}$

The steady-state real interest rate was set equal to 8.9 percent, as implied by the steady-state relationship $r=\theta Y / K-\delta$.

The utility function share parameter, $\alpha$, was set to imply that the average 
household member spends a fraction 0.3 of its time endowment in the labor market, a standard assumption for the United States that casual inspection of the available data suggests is reasonable for Argentina as well.

The coefficient of constant relative risk aversion was set at the level used in similar studies for the United States, that is, $\sigma=2$.

Finally, the persistence parameter $\rho$, the autoregressive component of the technology level (measured by the detrended Solow residuals), was determined from the autoregression (5) for the period 1951-79, after normalizing the initial Solow residual $z_{t}$ for the year 1951 to the value which makes the sample mean $\bar{z}$ of those residuals over that period equal to $z_{s s}$, the population mean arbitrarily set to the value such that output is equal to 1 in steady state. The estimated parameter value for $\rho, 0.56$, was actually obtained from the autoregression without a constant on the variable $\left(z_{t} / z_{s s}\right)-1$ that obtains, after some algebraic manipulation, from dividing both sides of equation (5) by $z_{s s}$, the steady-state technology level calculated as indicated earlier.

\section{Computation}

In our numerical experiments, we exploit the second welfare theorem to compute the solution of a dynamic stochastic general equilibrium neoclassical growth model. Since $\sigma>1,0 \leq \alpha \leq 1$, and $0 \leq \theta \leq 1$, the conditions for the second welfare theorem hold. In particular, the utility function is concave, and the production function defines a convex set for the resource constraint. This will guarantee that the solution to the social planner's problem can be decentralized as a competitive equilibrium. Notice that this problem is a version of the stochastic growth model first developed by Brock and Mirman (1972).

Our strategy to compute the only solution of the model is to find the value function and associated policy (or allocation) functions. Following Kydland and Prescott (1982), we substitute the resource constraint in the utility function and rewrite the resulting expression as a quadratic approximation around the steady state. This defines a linear-quadratic problem with well-known properties. In particular, the policy (or allocation) functions are linear in the state variables and can be readily computed with standard numerical methods (see Hansen and Prescott 1995).

Following the standard convention in that approach, the policy functions and resulting allocations are computed under the assumption that economic agents form expectations about the future rationally, based on the information available at the beginning of each period. This is in contrast with other papers in this volume that assume perfect foresight.

For that reason, and in the spirit of facilitating comparisons across countries that inspires this volume, we report in Appendix A the results for our 
simulations under the alternative but unrealistic assumption of perfect foresight. Here it suffices to mention that under this alternative assumption, some of our numerical experiments generated outcomes that differed from their stochastic counterparts in quantitatively significant ways. Such discrepancies might serve as a warning that considerable caution should be exercised in drawing conclusions from a perfect foresight model for volatile economies, subject to the same kind of wild depression and boom swings that Argentina experienced in the two decades studied here.

\section{Experiments}

\section{Purpose}

In this section, we ask what fraction of the growth rates of the relevant economic variables during the lost decade and subsequent recovery can be accounted for by a stochastic neoclassical growth model in which exogenous shocks to TFP are the only source of uncertainty. To that effect, as indicated in the previous section, we compute the equilibrium decision rules and simulate the path of the relevant variables of the model by feeding the measured TFP for the period 1981-97 into the equilibrium decision rules.

\section{Findings}

As Figure 2 makes apparent, the growth model with TFP taken as exogenous can account with remarkable precision for the dynamics of capital accumulation during Argentina's lost decade. Visual inspection of that figure, where the data, as in all subsequent figures, have been detrended by the TFP factor

\section{Figure 2. Capital stock}

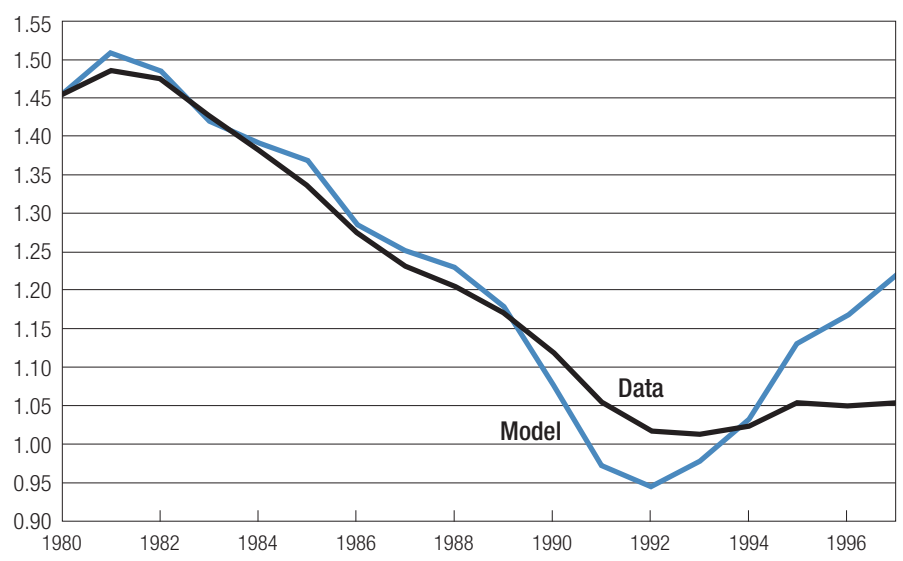


and working-age population growth, suggests that according to our numerical experiments, measured productivity can account for all of the decline in the capital stock during that depression. This ability of the model to capture the dynamics of investment during the lost decade is further stressed by Figure 3, plotting that variable as a percentage of GDP.

However, Figure 4 reveals that the performance of the model is not as stellar with respect to labor input, especially in the second half of the depression. According to the model, labor input should have declined at an average annual rate of about 0.1 percent between 1984 and 1990, instead of increasing

Figure 3. Investment as a percentage of GDP

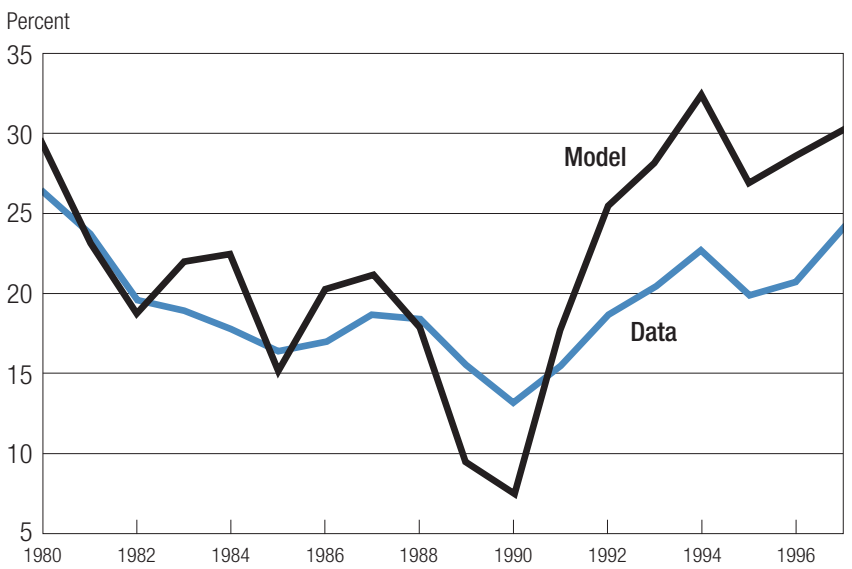

Figure 4. Labor input

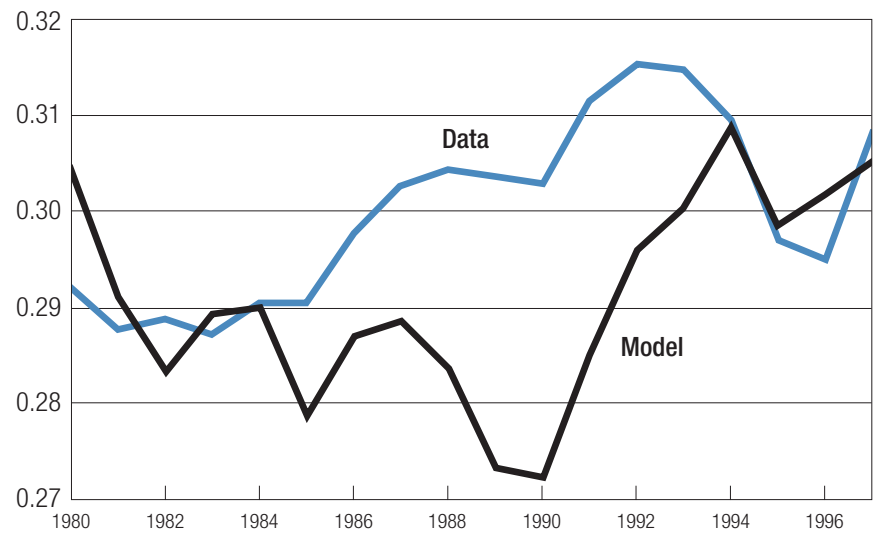


at an annual rate of 0.7 percent at that rate, as the data show.

Despite missing a nonnegligible fraction of the dynamics of the labor input, the neoclassical growth model predicts capital input so precisely that overall, TFP can account for practically all of the decline in GDP during the lost decade, as shown in Figure 5. By the same token, TFP accounted for almost all of the variations in the capital-output ratio over that same period (see Figure 6).

Overall, the results of the numerical experiments suggest that an economic agent equipped at the onset of the lost decade with the neoclassical growth

Figure 5. GDP per working-age population

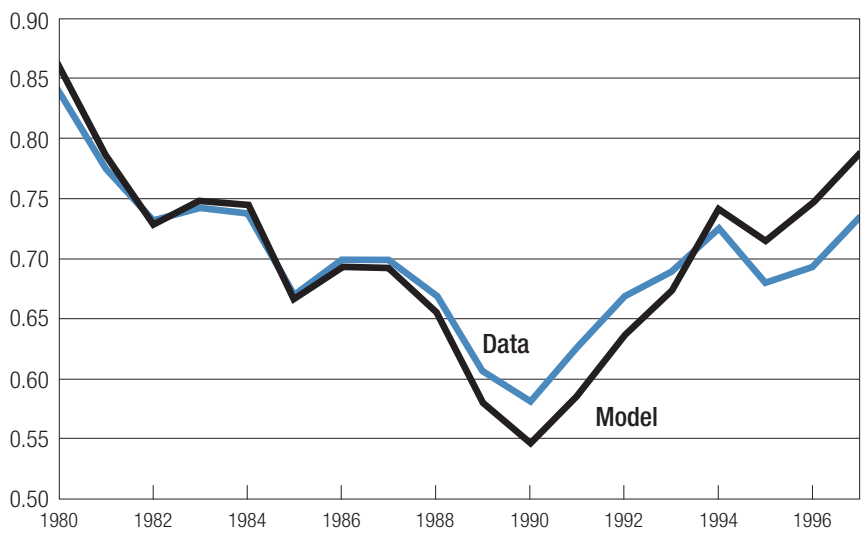

Figure 6. Capital-output ratio

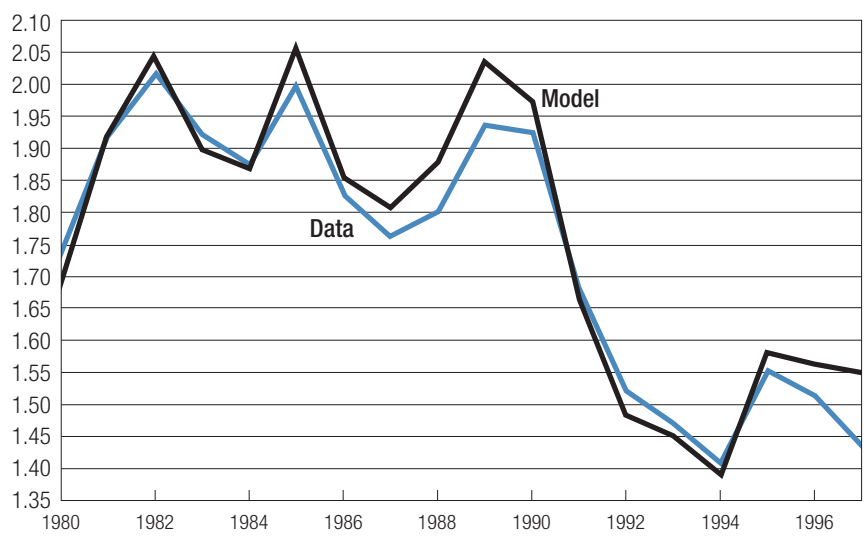


model and knowledge of the sequence of the TFP exogenous shocks that would hit the economy from then on would have been able to pick up remarkably well the dynamic paths of the capital stock, GDP, and the capital-output ratio during that depression. The same observer, on the other hand, would have missed the direction of change of labor input between 1984 and 1990, with the gap between observed and predicted values as large as 10 percent toward the end of the lost decade.

Perhaps somewhat surprisingly, inspection of Figure 5 suggests that whereas the neoclassical growth model seems to be able to account for the lost decade depression rather easily, the same is not the case for the expansion that followed.

Indeed, according to Figure 5, output during the recovery of the 1990s should have grown at an average annual rate of 5.4 percent, instead of the lower 3.4 percent at which it actually did. This prediction is a natural consequence of the overestimation over that period of the capital stock, which according to the model should have been about 15 percent higher than it actually was in the last year of that expansion, as shown in Figure 2. Equivalently, investment during the recovery of the 1990s should have been considerably higher, as shown by Figure 3. The resulting "excess capital shallowing puzzle" in the 1990s, reflected in a lower than predicted capital-output ratio and first discussed in Kydland and Zarazaga (2002b), is apparent also in Figure 6 . On the other hand, the model captures well the general upward trend in labor input during the expansion, with discrepancies between predicted and observed values in the order of 5 percent, half the size of the largest equivalent discrepancies during the lost decade.

In other words, the neoclassical growth model fails during the expansion years where it succeeds during the depression years, and vice versa. During the lost decade depression, the neoclassical growth model accounts extremely well for the evolution of capital input, although it underestimates labor input to a considerable extent. During the expansion, these results are reversed: the neoclassical model accounts rather well for labor input, but it overestimates capital input instead.

The apparent "failure" of the neoclassical growth model to account for the expansion following a recession does not seem to be unique to Argentina. As mentioned in the introduction, Cole and Ohanian (1999) reported a similar result for the United States. Thus, perhaps somewhat surprisingly, taken together these findings suggest that the relevant question for future research might be not so much whether the neoclassical growth model can account for depressions, but whether it can account for booms. A resolution of the "1990s puzzle" for Argentina could therefore have important implications for growth theory in general. 
In the next section we offer some conjectures that might help to explain the two "misses" of the neoclassical growth model reported above, that is, the underestimation of labor input during the lost decade and the overestimation of capital input during the subsequent expansion.

\section{Conjectures for the Resolution of the Anomalies}

The Lost Decade Excessive Employment Growth: The Employment Policies Conjecture

We found in our experiment that the model predicted that labor input should have declined overall by about 11 percent during the lost decade, whereas in the data, measured labor input actually increased about 4 percent. We conjecture that government policy in Argentina might help to explain this anomaly.

It has often been claimed that employment in provincial governments and state-owned enterprises in Argentina has been a covert form of unemployment insurance. Argentina was a heavily regulated economy until 1990, and it is well-known that "payroll-credited" unemployment insurance payments are the common device through which centrally planned economies can artificially increase employment or reduce measured unemployment.

Until recently, the information in the household surveyed did not distinguish employment in the private or the public sectors. This deficiency cannot be solved with data from other sources, because information on employment in the public sector is virtually nonexistent. The official statistics report systematic information on government employment only for the Central Administration, and even so, they do not always include contract personnel that usually fluctuate more than the permanent staff.

There is, however, some indirect evidence that suggests the magnitude of government employment programs. Information on the number of workers employed by provincial administrations from nonofficial sources, such as in Chisari et al. (1993), suggests that employment at the provincial and national administration levels may have represented between 10 and 13 percent of the total number of workers in the period of analysis. However, this figure does not include employment in the vast number of state-owned enterprises that were still under government control during the lost decade. There are no official records of the number of workers employed in those government conglomerates. One way to establish a rough upper bound for that figure is to assume that all the increase in unemployment between the end of 1990 and 1995 corresponded exactly to the number of workers who lost their "hidden unemployment" status when their firms were transferred to the private sector during the large-scale privatization process implemented over those years. 
Under that extreme assumption, the total number of workers in the public sector during the lost decade may have been on the order of 20-25 percent of total employment.

That fraction of total employment is not negligible and strongly suggests that government job programs may help to explain why employment did not decline during the lost decade, as predicted by the neoclassical growth model, but increased instead.

The policy implicit in those programs may have been to keep the job creation process going at a time when adverse and repeated productivity shocks would have led to a decline in overall employment. That is, negative productivity shocks like the ones observed in the lost decade in Argentina are typically associated with declines in real wages and, therefore, employment, as households devote a larger share of their time to leisure or nonmarket activities. The conjecture entertained here is that the government prevented this outcome through job creation initiatives that kept real wages above the marginal product of labor. Faced with this artificially high opportunity cost of leisure, a larger fraction of the population than otherwise chose to seek employment or remained employed in the sectors of the economy favored with explicit or implicit employment subsidies, mainly government agencies and conglomerates.

The appalling state of disarray of the public finances throughout the lost decade is consistent with that hypothesis. By all accounts, bloated public sector payrolls were a major contributor to the large fiscal deficits observed throughout that decade, and were ultimately responsible for the hyperinflationary outbursts of 1989 and 1990.

This conjecture is not without its challenges, because the introduction of employment subsidies will require the explicit introduction of the government budget constraint into the analysis. A more rigorous assessment of the ability of this "government jobs programs" hypothesis to explain away the excessive labor input anomaly of the lost decade will need first to measure the size of those programs and then quantify the effects on capital and labor inputs of the taxes needed to finance them. Collecting the necessary data to calibrate taxes, subsidies, and other relevant aspects of the job creation programs might prove a difficult but worthwhile research effort.

\section{The Excessive Capital Shallowing Puzzle of the 1990s: The Capital Taxation Conjecture}

As with the labor input growth anomaly of the lost decade just discussed, we conjecture that the excessive capital shallowing anomaly of the 1990s can eventually be explained away by government policies as well - in particular, government policies that directly or indirectly penalized the accumulation of capital. 
One possibility is that after the 1980s, Argentina switched to a regime of higher capital taxes. This conjecture is motivated by the recurrent episodes of bank deposit confiscations and sovereign debt defaults that Argentina has experienced in the last twenty years, the latest such episodes very recently, in 2001.

Higher taxes on capital are associated, of course, with a lower long-run capital-output ratio, whereas the model in this paper maintains that ratio unchanged at 2. Given the low levels of that ratio at the end of the lost decade, the model induces a strong "bounce-back" effect of capital input during the positive productivity shock years of the 1990s. But that effect would be dampened, more in line with the data, if taxes on capital or equivalent policies implemented over the two decades studied in this paper had reduced the long-run capital output ratio below the calibrated value of 2 . Notice that this conjecture is consistent with the previous one: taxes on capital are a good candidate to have been the source of funds to finance the job creation programs that might have been in place in the lost decade.

A related conjecture is based on the possibility of endogenous credit constraints of the type discussed in Kehoe and Levine (2001) and Alvarez and Jermann (2000). A growing body of literature suggests that small open economies face borrowing constraints that are binding not as much during downturns but during expansions (see, for example, Kehoe and Perri 2002). The reason for that counterintuitive outcome is that lenders do not have much interest anyway in investing in a country undergoing a period of low or declining productivity growth. By contrast, it is precisely at good times, when a country is experiencing favorable productivity shocks, that capital owners would like to invest in it to take advantage of the associated unusually high returns to capital. But potential investors are also aware that it is also at those times, when the capital stock would be particularly high if they proceeded naively, that countries prone to defaults and confiscations will be tempted the most to tax or confiscate capital. Despite the surge in productivity, those fears of opportunistic behavior will keep investment from rising as much as predicted by the default-free neoclassical growth model that the papers in this volume have used to organize the evidence.

Thus, a possible explanation of why investment remained so weak (relative to the model) in Argentina during the 1990s is that potential investors, their memories of that country's sovereign debt default in the mid-1980s and confiscation of deposits in 1990 still fresh, remained wary of similar episodes in the future and, accordingly, did not risk their capital in Argentina as much as the neoclassical growth model would predict. Indeed, those fears materialized in the dawn of 2002, when Argentina implemented the largest confiscation of deposits in its history and then proceeded to declare a massive default on its sovereign debt obligations. 
Exploring the extent to which this "risk of default" conjecture can resolve the excess capital shallowing puzzle of the 1990s for Argentina will eventually require considerable departures from the default-free world of the neoclassical growth model, a task that poses challenging theoretical and empirical issues that should be part of a research program we hope this paper will help to inspire.

\section{Conclusions}

This paper has explored the quantitative predictions of a rather parsimonious neoclassical growth model economy relative to the actual economy. Overall, our findings suggest that neoclassical growth theory can account for a great deal of Argentina's economic depression during the so-called lost decade of the 1980s. In that regard, the evidence does not seem to provide support for the hypothesis that economic depressions involve a breakdown or discontinuity in the behavior of economic agents or in the way they form expectations about the future.

Instead, we uncover a puzzle in the recovery that followed the depression: according to the neoclassical growth model, the capital stock should have grown at an average annual rate of about 4 percent during the expansion of the 1990s, whereas in the data (detrended), that stock instead remained flat throughout the whole recovery. Given a similar failure of the neoclassical growth model to account for the recovery that immediately followed the U.S. Great Depression, as reported in Cole and Ohanian (1999), we regard this "capital shallowing puzzle" of the 1990s as the potentially most interesting finding of this study and conjecture that accounting for it could prove a challenging task with important implications for growth theory.

The most puzzling aspect of the evidence, however, is why total factor productivity declined at an average rate of almost 2 percent for the unusually long time of a decade, the lost decade of the 1980s, and why it recovered so spectacularly at annual average rates of around 4 percent in the subsequent expansion of the 1990s. It would be tempting to link those wild swings in productivity to the distinctive policy regimes in place in those two periods: a heavily regulated and closed economy in default in the lost decade, a more open, less regulated economy engaged in ambitious privatization programs in the 1990s. However, such a relationship is not warranted by the maintained hypothesis in this paper of exogenous productivity shocks. Any progress in establishing such a link (perhaps along the lines of Parente and Prescott 1999) will undoubtedly constitute a huge step forward in understanding the ultimate determinants of the prosperity of nations. 


\section{Appendix A: Numerical Experiments under Perfect Foresight}

The results in the main body of the paper were derived under the assumption that agents form their expectations rationally, in the usual sense that their subjective beliefs about the likelihood of future events coincide with the actual probability distribution of such events.

Other papers in this volume, however, have adopted the alternative assumption that in making their decisions, the economic agents know the future with absolute certainty. In the spirit of facilitating comparisons across countries that inspire this volume, we report in this appendix the outcomes of the perfect foresight counterparts of the numerical experiments under rational expectations presented in the main body of the paper.

Unrealistic as it may be from a theoretical point of view, the perfect foresight assumption has the computationally appealing feature that the exact solution (to machine precision) for the equilibrium allocations of the neoclassical growth model can be computed quite easily. Indeed, by ex ante attaching probability one to the exogenous shocks observed ex post, the perfect foresight assumption expediently solves - at the cost of realism - the complex problem typically associated with the computation of mathematical expectations of endogenous variables in nonlinear problems. It is that complexity that oftentimes deters researchers from computing exact solutions to their models and leads them to resort instead to linear approximation techniques like the ones exploited in the main body of this paper. In the case of the parsimonious neoclassical growth model used here, the perfect foresight assumption reduces the problem of computing the equilibrium allocations and decision rules to the relatively simple task of finding the deterministic saddle-path solution of that model with standard numerical methods.

To that end, we first reduced the analytical solution of the deterministic versions of the neoclassical growth model in the main body of the paper to a system of two first-order nonlinear difference equations in capital and labor, with the initial condition for the capital stock, $k_{0}$, given by the level of capital stock actually observed at the beginning of 1980 . We then exploited the well-known saddle-path properties of the solution to that deterministic system (for parameter values in the usual range dictated by theory) to actually compute it. Namely, there is one and only one value for $l_{0}$ (the fraction of time spent in market activities) that, in combination with the given initial capital stock $k_{0}$, guarantees that the solution to the dynamic system of nonlinear difference equations converges to the balanced-growth path. Initial values of $l_{0}$ different from the saddle-path solution $l_{0}^{*}$ are associated either with explosive paths, along which the capital stock grows at rates progressively higher than those implied by the balanced-growth path, or with implosive ones, along which the initial capital is run down to zero. Exploiting this property, we first identify an initial value $l_{0}^{e}$ for $l_{0}$ associated with an explosive path and another one, $l_{0}^{i}$, associated with an 
implosive path. The initial value saddle-path solution must lie somewhere in between, and can be found numerically, therefore, with the bisection method we used in this appendix. In implementing that method, we adapted to the utility function used in this paper an algorithm that Alpanda and Amaral developed to compute the perfect foresight experiments in the paper by Hayashi and Prescott in this same volume. ${ }^{7}$

The parameter values for our perfect foresight experiments were, of course, kept the same as in the experiments under rational expectations, except that the algorithm did not require the no-growth representation of the model economy used for the computations under rational expectations. Accordingly, no transformation of the parameter $\beta$ and growing variables was needed.

Figure 2A. Perfect foresight: capital stock

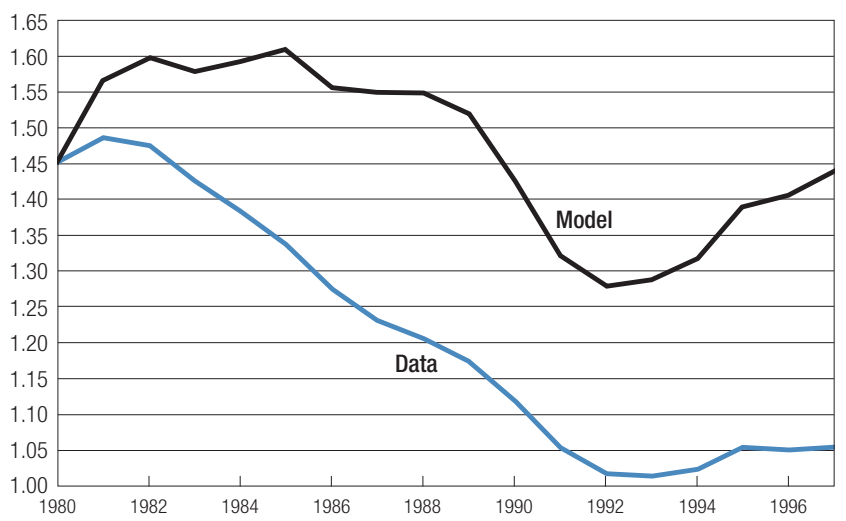

Figure 3A. Perfect foresight: investment as a percentage of GDP

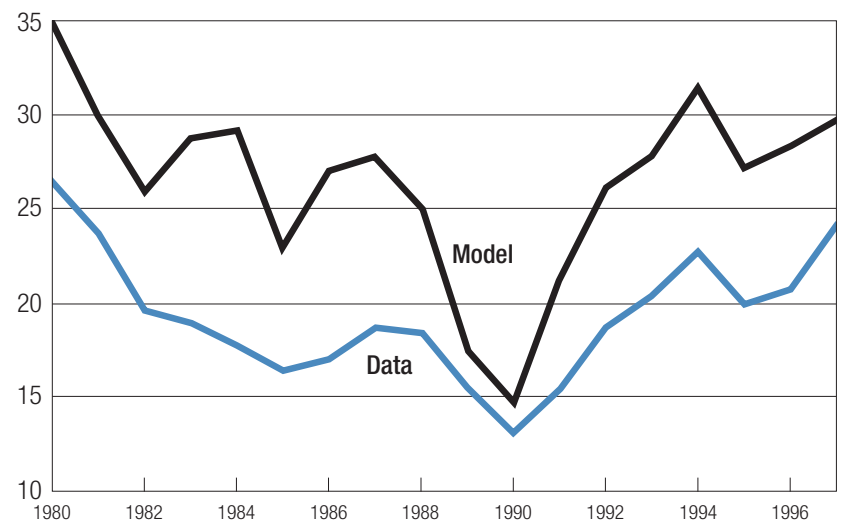


Figures 2A, 3A, 4A, 5A, and 6A are the perfect foresight counterparts of the figures labeled with the same numerals in the text. As in the text, the data and model predictions have been detrended by the applicable balanced-growth rates.

Comparison of Figures 5 and 5A immediately reveals that the results of the numerical experiments under perfect foresight are different from the stochastic version reported in the main body of the paper. That discrepancy can be traced to a large extent to the capital stock in Figure 2A, reflecting the behavior of investment in Figure $3 \mathrm{~A}$. While the stochastic version of the model predicts the decline of the capital stock during the lost decade quite accurately, the perfect foresight version seriously underestimates that decline. By contrast, the perfect foresight version overestimates

Figure 4A. Perfect foresight: labor input

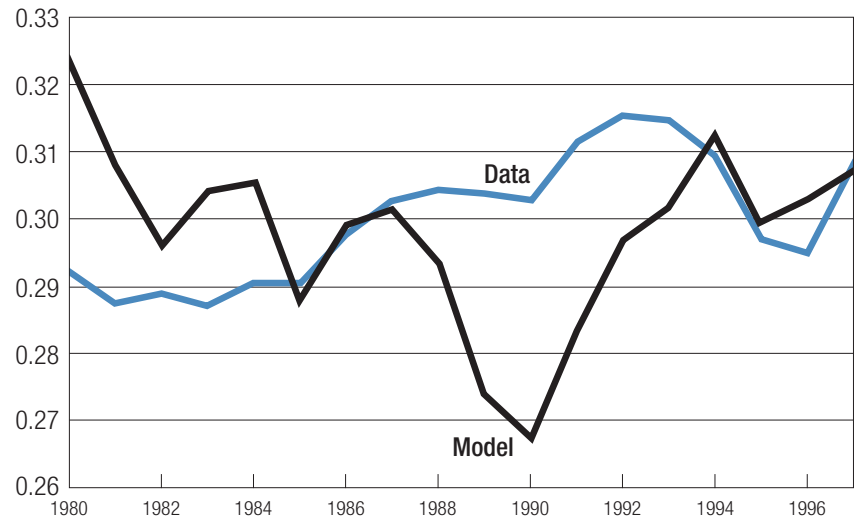

Figure 5A. Perfect foresight: GDP per working-age population

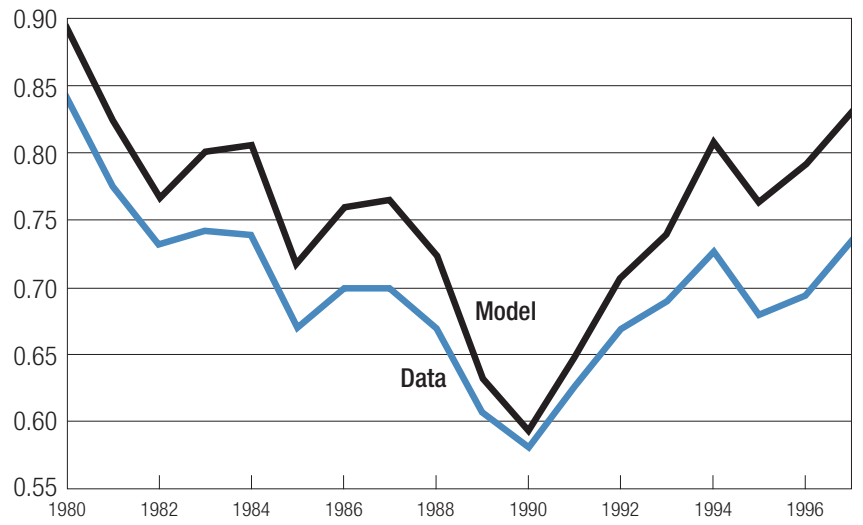


Figure 6A. Perfect foresight: capital-output ratio

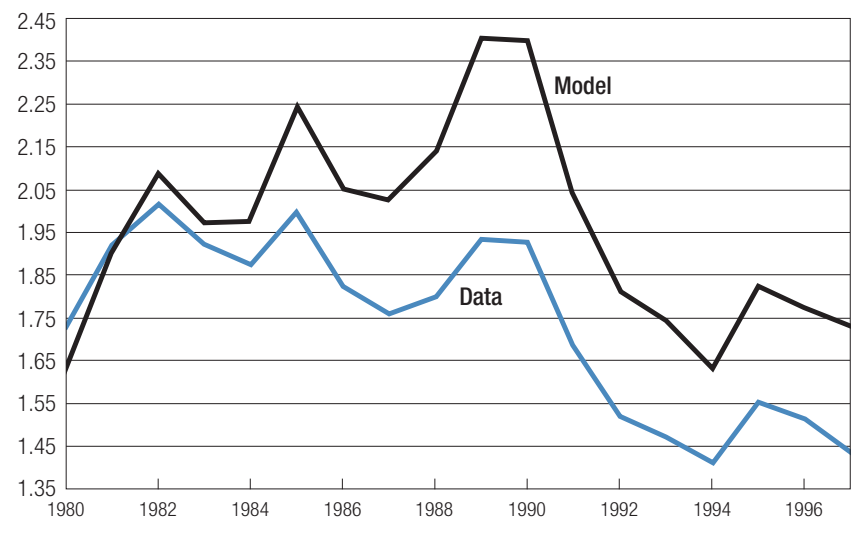

the decline of labor input over that same period by two-thirds more than the rational expectations counterpart of the same experiment.

In future research we plan to establish whether the differences between the perfect foresight and rational expectations numerical experiments reflect the different assumptions regarding expectations or fairly large approximation errors in the linear quadratic algorithm used to compute the rational expectations experiments. The latter possibility is not totally implausible, given the large deviations that the Argentine economy experienced from the steady state in the period under analysis. 


\section{Appendix B: Data Sources and Methodology}

\section{Real GDP}

The Real GDP series for the period 1980-97, in 1986 prices, was taken from Heymann 2000 . The series was extended back to the year 1950, applying the growth rates of the Real GDP series for the period 1950-70, in 1960 prices, and for the period 1970-80, in 1970 prices, reported in ECLAC-CEPAL 1988.

\section{Population}

Total and working-age population series were estimated by geometric interpolation of quinquennial data reported in CELADE 2002.

\section{Labor Input}

For most of the period under study, Argentina did not have reliable statistics on hours worked, except for a few industries. Official statistics on the aggregate level of employment were not available either until 1980. There are, however, partial series of employment that made it possible to measure labor input as number of workers, starting from the aggregate level of employment for the year 1950 reported in Hofman 2000, Table 4.4, page 53. The series was extended to the year 1997 by applying to that 1950 level the growth rates of the employment series in Elías 1992 for the period 1951-79 and in MECON 2000 for the period 1980-97.

The series reported by Elías corresponds to employment of wage earners, constructed using information published by the Central Bank of Argentina, after filling the missing observations by interpolation of labor force participation rates extracted from population censuses run every ten years. ${ }^{8}$ This procedure may have underestimated actual employment growth rates because labor force participation rates include both employed and unemployed workers, and unemployment rates experienced a continued decline in Argentina between the year they started to be measured (1963) and the last year of Elías's employment series (1979). As a result, an upward bias may be present in the Solow residuals estimated for that period.

Growth rates for the period 1980-97 were based on annual employment figures, calculated as an arithmetic average of all the observations available for each year in MECON 2000. Data from this source correspond to employment in about thirty urban conglomerates that started to be covered systematically by the Encuesta Permanente de Hogares (Permanent Household Survey) in 1980. The Ministry of Economy uses those surveys to calculate, for each urban center, the fraction of individuals in all households interviewed that have reported some form of employment. It then applies that proportion to the overall population of the corresponding metropolitan conglomerate, to arrive at an estimate of the total number of employed there. The number of employed for urban areas not covered by the survey is estimated by applying to the estimated total population in those areas, the average of the employment coefficient 
just described, weighted by the population of all urban centers other than the capital of the country, the Buenos Aires Metroplex area. It should be mentioned that one difficulty with those surveys is that it is not clear how well the reporting households represent the characteristics of the whole population, and in particular, of cities and rural areas not covered by the surveys.

The actual employment variable used for the computations was $E_{t} h / W_{t}$, where $E_{t}$ is the number of persons employed, $W_{t}$ is the population in working age, and $h$ is a normalizing constant, chosen so that the mean of the variable $E_{t} h / W_{t}$ for the period under study, 1980-97, is equal to 0.3 , the fraction of total available time that it was assumed households devote to work in steady state. The constant $h$ is a synthetic variable that stands in for the missing information in hours worked and can be interpreted as the fraction of the total individual available time that each household member devotes to work when employed. Taking into account that on a per-person basis a household has about one hundred hours of productive time per week (see Prescott 2004), the calibrated value for $h, 0.44$, implies a workweek of approximately forty-four hours.

\section{Capital and Investment}

Given the lack of official series, the capital stock was calculated by applying the permanent inventory method to the investment series for different types of assets, discriminated in residential structures, nonresidential structures, and machinery and equipment.

Following accepted practice (see Hofman 1992 and ECLAC-CEPAL 1996), each asset class $i$ was assumed to be completely worn out, that is, to have no scrap value, after $T(i)$ years of service, with a useful lifetime of fifty years for residential structures, forty years for nonresidential structures, and fifteen years for machinery and equipment. ${ }^{9}$ Depreciation in the meantime is assumed to proceed at geometric rate $\delta_{i}$. Taking into account the time-to-build assumption that the services from investment in period $t$ become available at $t+1$, this truncated geometric depreciation scheme implies that the residual value at period $t$ of productive capital of type $i$ installed $n$ periods before is given by $I_{i, t-n}\left(l-\delta_{i}\right)^{n}$, where $\delta_{i}$ is the depreciation rate and $I_{i, t-n}$ the investment in asset type $i$ in period $t-n, n \leq T(i)$. The implicit depreciation rate $\delta_{i}$ was chosen so that the residual value of the asset type $i$ at the last year of its useful life is given by $I_{i, t-T(i)} / T(i)$, that is, to satisfy the equation $(1-\delta)^{T(i)}=1 / T(i)$. This condition implied annual depreciation rates of 7.53 percent for investment in residential structures, 8.81 percent for investment in nonresidential structures, and 16.52 percent for investment in machinery and equipment. ${ }^{10}$

The permanent inventory method with the assumptions just discussed was applied to the investment series, available or constructed as follows.

\section{Investment in Machinery and Equipment Series}

For the period 1980-97, obtained as the difference between Gross Total Fixed Investment and Investment in Structures in 1986 prices, as reported in Heymann 2000. As with the case of Real GDP, this series was spliced with previous ones, 
by applying the growth rates of the machinery and equipment investment series reported in ECLAC-CEPAL (1958) for the period 1900-50, in 1950 prices, and in ECLAC-CEPAL (1988), for the period 1950-70, in 1960 prices, and for the period $1970-80$, in 1970 prices.

\section{Investment in Nonresidential and Residential Structures Series}

Argentina's national accounts report investment in total structures, but the discrimination between the nonresidential and the residential component is available only for certain periods. A possible option to confront this difficulty is to ignore any distinction between nonresidential and residential components of investment in structures. ${ }^{11} \mathrm{An}$ alternative followed here, based on standard practice by other researchers, was to assume that the nonresidential component is a fixed percentage of overall investment in structures. To that end, based on the considerations in Hofman (1992; see comments section in data diskette), for the period 1980-97 it was assumed that 54 percent of investment in structures went to its nonresidential component and the remainder to its residential component. For the period 1900-79, residential investment was assumed to grow at the same rates as the nonresidential investment series reported in Hofman 1992. This assumption, implied by the fixed coefficient allocation approach applied by Hofman 1992 to the period 1955-69, was applied here as well for methodological consistency to all years prior to 1955 .

It is important to emphasize that implicit in the standard growth accounting method used to measure TFP is the assumption that all factors of production, in particular capital input, are fully utilized. However, independent evidence suggests that capital utilization in Argentina declined substantially during the lost decade and recovered significantly in the subsequent expansion. Equivalently, capital input may have fallen more during the lost decade than our permanent inventory method measures suggest. Likewise, it may have increased more than measured during the subsequent expansion. Although there are no widely accepted measures of capital input adjusted for capital utilization, it is important to keep in mind that an unknown fraction of the large TFP shocks reported in Table 1 may be the result of changes in capital utilization missed by the permanent inventory method.

\section{Notes}

Reprinted from Review of Economic Dynamics, Vol. 5, Finn E. Kydland and Carlos E. J. M. Zarazaga, "Argentina's Lost Decade," pages 152-165, copyright 2002, with permission from Elsevier. The views expressed herein are those of the authors and not necessarily those of the Federal Reserve Bank of Minneapolis, the Federal Reserve Bank of Dallas, or the Federal Reserve System.

We are grateful to Sami Alpanda, Fernando Alvarez, Pedro Amaral, Mark Gibson, Tim Kehoe, Jim MacGee, Ed Prescott, and the participants at the "Great Depressions of the Twentieth Century" conference in October 2000 for extremely useful and constructive comments and suggestions on an earlier version of this paper. We also wish to acknowledge the diligent research assistance of Elias Brandt and Eric Millis at different stages of this project. 
1. See the introductory chapter by Kehoe and Prescott in this volume.

2. As explained in the introductory chapter of this volume, this "intensive" version of an otherwise standard growth accounting exercise is obtained by first multiplying both sides of the production function (1) by $N^{(\alpha-1)} / Y^{\alpha}$ and then solving the resulting expression for GDP per capita.

3. Recall that the gross TFP factor is equal to $(1+\gamma)$, which implies that total factor productivity, as calculated from $(1+\gamma)^{(1-\theta)}=(1-0.0025)^{(1-0.4)}$, declined at an average annual rate of 0.15 percent in the period 1969-79.

4. By the arithmetic of the previous note, this explains an average annual total factor productivity decline of around 2 percent for the lost decade.

5. However, sensitivity analysis suggests that the results are quite sensitive to the choice of this value.

6. De Gregorio and Lee (1999) find that the labor share could be as large as 0.7, according to the indirect measure proposed by Sarel (1997).

7. We are thankful to Sami Alpanda and Pedro Amaral for having provided us the algorithm they developed in MATLAB code. The adaptation used for this appendix is available from us upon request.

8. As documented by Elías in personal correspondence with the authors.

9. Capital stock estimates for the United States assume asset life spans that are roughly in line with the ones used in this paper.

10. The truncated geometric depreciation scheme used here may underestimate steady-state capital stock by a fraction $\left(1-\delta_{i}\right)^{T(i)+1}$ of the capital stock calculated with the perpetual geometric depreciation scheme assumed by the neoclassical growth model. The potential underestimation is relatively minor for the particular depreciation parameter values used here (around 5 percent for the machinery and equipment component and 2 percent for the structures component).

11. This was implicitly the procedure adopted in Kydland and Zarazaga (2002a).

\section{References}

Alvarez, Fernando, and Urban J. Jermann. 2000. Efficiency, equilibrium, and asset pricing with risk of default. Econometrica 68 (July): 775-97.

Brock, William A., and Leonard J. Mirman. 1972. Optimal economic growth and uncertainty: The discounted case. Journal of Economic Theory 5 (June): 479-513.

CELADE (Centro Latinoamericano y Caribeño de Demografia - Latin American and Caribbean Demographic Centre). 2002. Latin American and Caribbean: Population estimates and projections 1950-2050. Demographic Bulletin 35 (January).

Chisari, Omar; José Fanelli; Roberto Frenkel; and Guillermo Rozenwurcel. 1993. Argentina and the role of fiscal accounts savings and investment requirements for the resumption of growth in Latin America. In Savings and investment requirements for the resumption of growth in Latin America, ed. Edmar Bacha. Washington, DC: Inter-American Development Bank. Distributed by Johns Hopkins University Press, Baltimore. 
Cole, Harold L., and Lee E. Ohanian. 1999. The Great Depression in the United States from a neoclassical perspective. Federal Reserve Bank of Minneapolis Quarterly Review 23 (Winter): 2-24.

Cooley, Thomas F., and Edward C. Prescott. 1995. Economic growth and business cycles. In Frontiers of business cycle research, ed. Thomas F. Cooley. Princeton, NJ: Princeton University Press.

De Gregorio, José, and Jong-Wha Lee. 1999. Economic growth in Latin America: Sources and prospects. Documento de Trabajo No. 66, Serie Economía, December, Centro de Economía Aplicada, Facultad de Ingeniería Industrial, Universidad de Chile, Santiago, Chile.

ECLAC-CEPAL (Economic Commission for Latin America and the Caribbean-Comision Económica para América Latina). 1958. El desarrollo económico de la Argentina. Santiago, Chile: ECLAC-CEPAL.

1988. Estadísticas de corto plazo de la Argentina: Cuentas nacionales, industria manufacturera y sector agropecuario pampeano. Documento de Trabajo 28. Buenos Aires: CEPAL Buenos Aires.

1996. Strengthening development: The interplay of macro- and microeconomics. Santiago, Chile: United Nations, ECLAC.

Elías, Víctor J. 1992. Sources of growth: A study of seven Latin American countries. San Francisco, CA: ICS Press.

Hansen, Gary D., and Edward C. Prescott. 1995. Recursive methods for computing equilibria of business cycle models. In Frontiers of business cycle research, ed. Thomas F. Cooley. Princeton, NJ: Princeton University Press.

Heymann, Daniel. 2000. Políticas de reforma y comportamiento macroeconómico. In Desempeño económico en un contexto de reformas, ed. Daniel Heymann and Bernardo Kosacoff. Buenos Aires, Argentina: Editorial Universitaria de Buenos Aires (EUDEBA).

Hofman, André A. 1992. Capital accumulation in Latin America: A six country comparison for 1950-89. Review of Income and Wealth 38 (December): 365-401. Annex A, Tables AR1 and AR2, column 3, as extracted from diskette accompanying the article.

Hofman, André A. 2000. The economic development of Latin America in the twentieth century. Northampton, MA: Edward Elgar.

Kehoe, Patrick J., and Fabrizio Perri. 2002. International business cycles with endogenous incomplete markets. Econometrica 70 (May): 907-28 .

Kehoe, Timothy J., and David K. Levine. 2001. Liquidity constrained markets versus debt constrained markets. Econometrica 69 (May): 575-98.

Kehoe, Timothy J., and Edward C. Prescott. 2002. Great depressions of the twentieth century. Review of Economic Dynamics 5 (January): 1-18.

Kydland, Finn E., and Edward C. Prescott. 1982. Time to build and aggregate fluctuations. Econometrica 50 (November): 1345-70.

Kydland, Finn E., and Carlos E. J. M. Zarazaga. 2002a. Argentina's lost decade. Review of Economic Dynamics 5 (January): 152-65.

. 2002b. Argentina's recovery and excess capital shallowing of the 1990s. Estudios de Economía (Universidad de Chile). 
Great Depressions of the Twentieth Century

MECON (Ministry of Economy, Argentina). 2000. Economic report, first quarter 2000. Vol. 9, No. 33 (July).

Parente, Stephen L., and Edward C. Prescott. 1999. Monopoly rights: A barrier to riches. American Economic Review (December): 1216-33.

Prescott, Edward C. 2004. Why do Americans work so much more than Europeans? Federal Reserve Bank of Minneapolis Quarterly Review 28 (July): 2-13.

Sarel, Michael. 1997. Growth and productivity in ASEAN countries. IMF Working Paper 97/97. 